
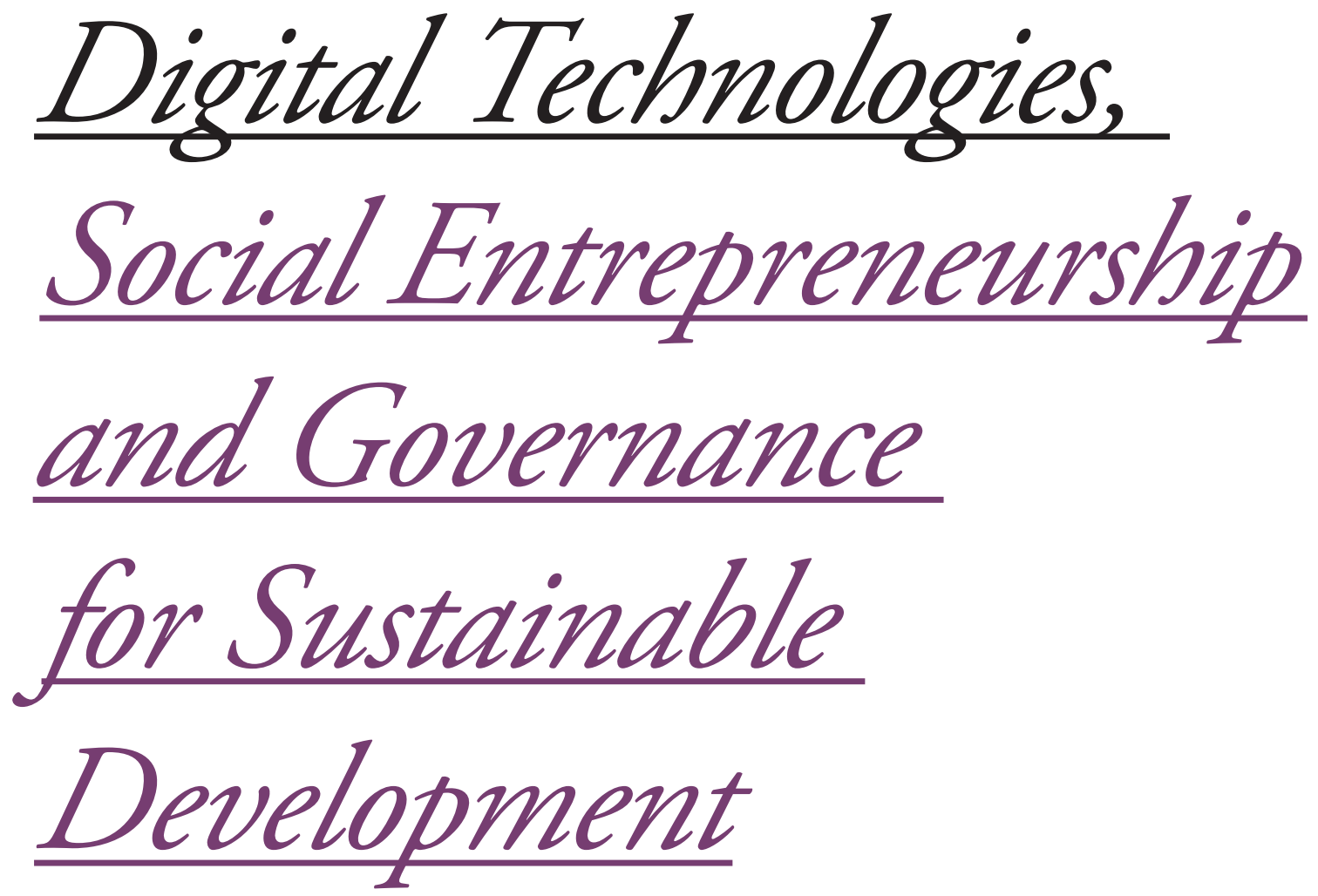

DR. MATEJ MAKAROVIČ

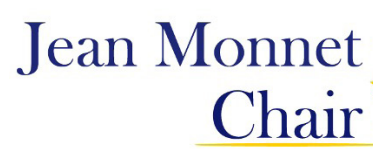

Chair

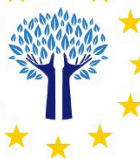

European Transnational Governance for Sustainable Development as the articles for this thematic issue were collected within this project.

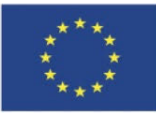

With the support of the

Erasmus+ Programme

of the European Union

The European Commission support for the production of this publication does not constitute an endorsement of the contents which reflects the views only of the authors, and the Commission cannot be held responsible for any use which may be made of the information contained therein.

ə) Open Access. () 2022 Matej Makarovič. This is an open access article distributed under the Creative Commons AttributionNonCommercial-NoDerivs license (c) Br (http://creativecommons.org/licenses/by-nc-nd/4.0/). 


\section{DIGITAL TECHNOLOGIES, SOCIAL ENTREPRENEURSHIP AND GOVERNANCE FOR SUSTAINABLE DEVELOPMENT}

\begin{tabular}{|c|c|}
\hline \multirow{3}{*}{ Abstract } & Maria Skivko* \\
\hline & Samara National Research University, Russia \\
\hline & $\begin{array}{l}\text { In order to encourage and develop technological and social innovations, it is relevant to create and support businesses that } \\
\text { foster such innovations. Additionally, sustainable development requires business transformation to complement several social, } \\
\text { economic, or ecological problems. Social entrepreneurship as a type of business focuses on solving social, cultural, or environ- } \\
\text { mental problems and creating effective responses to such challenges. By providing new working places, offering creative solu- } \\
\text { tions to everyday problems, and highlighting the importance of social solidarity, social entrepreneurship contributes to sustain- } \\
\text { able development goals. In these conditions, the impact of digitalization is unavoidable: it relates technologies, consumers, and } \\
\text { business strategies and stimulates necessary changes. This research emphasizes the use of digital technologies and applying } \\
\text { the principles of digital culture by social business to foster technological innovations and contribute to the realization of sustain- } \\
\text { able development goals. The examples from the Russian social entrepreneurship applying digital innovations illustrate this idea. }\end{array}$ \\
\hline Keywords & social entrepreneurship $\cdot$ digital technologies $\cdot$ sustainable development $\cdot$ sustainability $\cdot$ innovations \\
\hline
\end{tabular}

\section{Introduction: Sustainable Development and the Path to Changes}

Global sustainability discussion embraces many topics and areas of human activities. From the climate changes and global warming danger that concern everyone to specific challenges to support local producers or minimize waste production, sustainable development goals constantly require new solutions, approaches, and innovative ideas for everyday routines. Large corporations contribute by supporting charity funds, local environmental initiatives, implementing the concept of corporate social responsibility, and competing with others for the best sustainable business approach. It is a transformation process that requires a lot of financial, human, time, and innovative resources. Small- and medium-sized companies, in turn, have fewer opportunities to adapt to the global sustainable discussion; however, some of them, step-by-step implement some positive, sustainable changes at the levels of developing an idea, supply chain, production process, delivery services, or sales.

The more sustainable discussion attracts the attention of different national and international institutions and social groups, the more urgent is the demand for innovative ideas.
Social and technological innovations have become today an instrument for answering various questions; besides, these innovations can get sufficient governmental and administrative support. Nevertheless, there is a necessity to develop new business models and reorganize businesses to implement innovations faster, more easily, and more efficiently.

Therefore, social entrepreneurship seems to be the correct direction for businesses to accomplish sustainable development goals. Social entrepreneurship can address hybrid business models and innovative business ecosystems by applying business knowledge to creating sustainable solutions for complex social and environmental problems.

Furthermore, global sustainability discussion provokes new market threats and opportunities, stimulates high concurrence in the innovations field, and invites businesses, government, and nonprofit organizations to collaborate and exchange ideas and experiences. Achieving sustainable development goals is also about the growing importance of social capital: people can create and lead those changes that bring positive social and economic transformation. In other words, individual ideas can answer individual requests.

However, the realization of sustainable development goals would be less efficient and successful without digital technologies. Digitalization and technological progress brought 
large corporations that integrated sustainability principles in their digital transformation to the next qualitative level. Furthermore, even for small companies and social startups, it became possible to digitalize business, use mobile applications for sales and customer communications, and develop various technologies to answer consumer demands. This article focuses on the possibilities for applying digital technologies in social business in order to achieve sustainable development goals. It describes the importance of social and technological innovations in modern business. Additionally, it emphasizes the specificity of driving social business toward sustainable development. Furthermore, the article explains the possibilities for digital technologies to implement sustainable changes in the consumer market. More precisely, the research case concerns social entrepreneurship in Russia, describing challenges and prospects for its further development.

\section{Driving Business with Social and Technological} Innovations

Because of the influence of sustainable development discussions, modern businesses have to implement significant changes, search for new business models and economic profits, adopt new technologies, and answer current consumer demands. Globalization, digitalization, disruptive technologies, and digital culture require business structures to adopt innovative ideas as well as human capital in order to operate in times of uncertainty and social and economic transformation.

Some business models emphasize the importance of technological innovations as their key idea and as the driving force to development and monetisation (BadenFuller and Haefliger 2013, 421-3). Technologies affect the company's image, reputation, and customer interest. Moreover, technological progress creates new business models. Some scholars emphasize the importance of designdriven innovations that promote startups and strengthen the system of values concerning the design and innovative ideas (Moroni, Arruda, and Araujo 2015, 2201-04). Furthermore, technological innovations work efficiently to meet sustainable development goals; especially during the COVID-19 pandemic, technologies ensure consumer demands, current global restrictions, and health and safety rules (Khan et al. 2021, 8479).

Social innovations put forward new ideas or a combination of existing elements as a solution for common needs. These ideas grow as initiatives from individuals, social leaders, or as a result of social movements, market demands, political changes, or organizational needs. The proposed solutions embrace the problems of social justice, education, transportation system, health organizations, etc. Moreover, social innovations are used in technology, public policies, design, urban development, and community development.

Social innovations can solve some global problems, for instance, climate change, rational resource use, aging, and inequalities. Moreover, there is a necessity for a new economy type that can support and develop such social innovations and successfully operate within the global market. Furthermore, social innovations can offer individual solutions for certain societies, nations, and regions whose boundaries traditional business models usually cannot overcome. Therefore, in order to develop and promote such social innovations, there is a need of support from certain social institutions and new ways of growing and maintaining innovators (Mulgan et al. 2007, 27-32).

Social innovations appear in the activities of NGOs, the public sector, social movements, networks, and markets. They are usually connected with strategic actions regarding poverty, discrimination, social exclusion, and empowering minorities. Traditionally, social innovations are considered marketdriven and among other economic practices; however, some scholars emphasize the priority of social business over social movement by having more power for proceeding changes (Jessop et al. 2013, 2-5). It is necessary to analyze and define the understanding of the connections among social changes, social transformation, and social innovations.

Some researchers aim to explain social innovations in the political, academic, and practitioner's contexts (Choi and Majumdar 2015, 10-22). The key factors that characterize social innovations consist of the procedure of formalization, the process of change, and essential social outcomes. Other scholars research the specificity of communication in social innovations projects and analyze the different effects of communication strategies (Salim Saji and Ellingstad 2016, 260-4). Moreover, researchers question innovation policies and emphasize the necessity of developing an understanding of the innovation paradigm that will support the development of social innovations (Howaldt et al. 2016, 24-27).

\section{Basic Ideas of Social Entrepreneurship}

Among various social entrepreneurship definitions, it is possible to highlight the intention to create social value by solving social problems. It is innovative, resourceful, and results-oriented; it develops, funds, and implements solutions to social, cultural, or environmental issues. Social entrepreneurs create new ideas or redesign existing ones, use various opportunities to complete a social mission, and engage in the innovation process. Social business is sometimes quite risk-taking and full of accountability; social entrepreneurs usually address unusual problems and requests through market methods and 
innovative ideas. Furthermore, the idea of "social« in social entrepreneurship emphasizes the organizational purpose of contributing to social equity compared to traditional commercial business (Blaga 2018, 23-25). Nevertheless, social business does not exclude several financing and marketing activities and corresponding business models. One specific concern about business models for social entrepreneuship is how social value is created and can be converted into financial profit.

Using market-driven strategies for tackling critical social issues, social entrepreneurs can contribute to the sustainable development global discussion. The ideas that contribute to local problems offer an approach to personalized demands that can be competitive enough and economically profitable. So, social enterprises have the chance to ensure the ways to achieve sustainable development (Rahdari, Sahar, and Moradi 2016, 355-8). Social businesses engage in fighting poverty and hunger, for instance, by providing working places and nutrition for socially oppressed or marginalized groups; in promoting dignity and equality by attracting attention to socially oppressed people; in popularizing an idea of sustainable consumption and production by supporting local business and promoting artisanal crafts. Moreover, it involves ideas such as integration, interconnection, joint mobilization, and inclusiveness.

Social responsibility and implementation of social values into social business models and processes positively influence the development of social entrepreneurship. Additionally, business models of social entrepreneurship can use all their competitive advantages in order to create social value by fulfiling social needs, optimizing financial security, and applying sustainable solutions. Moreover, social business leaders can promote major business transformation by providing small solutions for local problems (Muralidharan and Pathak 2018, 567). The interconnection between cultural leadership styles and societal sustainability reflects the demand for social and economic changes and human power to execute them.

The close connection between business and society and the expectations from customers and policymakers stress the need for transformation in traditional business models for sustainable development goals (Lehtimäki et al. 2021, 172-5). Social entrepreneurs as change agents respect the collective more than self-interest and execute a social mission by providing positive changes in different areas.

\section{Digital Technologies and Social Entrepreneurship}

Digital technologies deliver considerable changes in the global society. Their impact can be measured not only in companies' profits and ratings but in social categories, too. Digital technologies link different people worldwide and overcome geographical distances and time differences, allow efficient networking and idea exchange, combine human, financial, and intellectual efforts at the local and global levels to create innovative solutions for social needs (Prodanov 2018, 128-34). Furthermore, digital technologies allow social entrepreneurs to more easily exchange data, reach more potential clients, and popularize a product or service with fewer costs. Personalization and micromarketing structure a new business model for more efficient work and better reaction to social demands.

Today, social business actively applies various digital technologies as developing a new technology or using the existing ones to implement solutions to problems. Moreover, digital tools for interaction and information exchange simplify marketing, advertisement, and communication strategies for social entrepreneurs. According to a Social Innovation Mapping Report by the Intel Foundation and Ashoka (Changemakers n.d.), the best social entrepreneurship practices create social value by applying digital technologies to expanding the notion of digital literacy, attracting stakeholders, adjusting relations with marginalized groups, and effectively communicating results of that work.

Furthermore, digital technologies simplify and support social entrepreneurship practices, from crowdfunding platforms to find investors, to developing a particular technology as a solution for a specific demand. Some scholars define a particular hybrid type of social business as digital social entrepreneurship (Masiero and Ravishankar 2019, 300305). It means entrepreneurship as a business model that creates social values and executes social missions within digital technologies. Digitization of social entrepreneurship opportunities, resources, governance, and value measurement resolve some difficulties in social opportunities transformation, the high cost of resources, stakeholders communication, and social value evaluation (Liu et al. 2020, 5-8). Furthermore, other scholars denote that digitalization and social entrepreneurship can improve national well-being while competing with weak social institutions (Torres and Augusto 2020, 120-279).

In the same way, sustainable practices in business that apply and extend digital technologies can join the market of social entrepreneurship initiatives (Gregori and Holzmann 2020, 122817). Dealing with social and environmental challenges, sustainable entrepreneurs generate positive social and environmental impacts by implementing profitable and innovative business models. Digital technologies, for instance, digital platforms, software, applications, or infrastructure, simplify access to various sustainable actions; they provide an open, accessible interface to connect, communicate, and share sustainable ideas and projects.

The restrictions of the COVID-19 pandemic and the rise of a knowledge economy based on innovative ideas and intellectual capital stimulated the development of social 
entrepreneurship initiatives (Calderini et al. 2021). Social-tech entrepreneurship operates with a new form of management that deploys technology-driven solutions for social needs.

The most famous example of social entrepreneurship that efficiently uses digital technologies is the case of microfinancing at the Grameen Bank, led by Muhammad Yunus, a Bangladeshi social entrepreneur, banker, and economist. His main idea was to give loans to the too poor entrepreneurs worldwide who could not receive traditional bank loans. His efforts to proceed with social and economic development through microcredits for people to become self-employed helped many communities to recover. For pioneering the ideas of microcredit and microfinance, he was awarded the Nobel Peace Prize.

\section{Research Case on Social Enterpreneurship in Russia: Obstacles and Possibilities}

In order to characterize the context for social entrepreneurship, it is necessary to define the social needs to be addressed, a social mission, and the environmental dynamics (Goyal and Sergi 2015, 270-1). Social entrepreneurship has more chances than do governmental structures to solve local problems with mobility barriers, social acceptance, low literacy levels, limited infrastructure, lack of complementary offerings, etc. Some examples for social business relate the robotics and sensors for personalized care for people with reduced mobility; mobile communications solutions, the use of drones for delivery services in remote areas; and developing digital platforms to attract makers and people with disabilities for creating specific goods and services.

This paper describes some cases of social entrepreneurship in Russia with an application of digital technologies. As some scholars note, the lack of legal framework for the interaction of different institutions and legal policies for regulating the legislation to support small- and medium-sized businesses constrain the full-fledged development of Russian social business (Akhmetshin et al. 2018, 1-5; Moskovskaya and Soboleva 2016, 685-8). Therefore, social entrepreneurship in Russia is still mainly connected with and understood as some activities to provide social services from nonprofit organizations. Due to the vast state territory and limited state budget, there are enough social problems without proper solutions or with ineffective solutions from the state.

Additionally, there are some difficulties with the economic and institutional environment to support social business. One of the significant problems is the type of economy needed to develop social entrepreneurship: as some scholars mention, the Russian economy is rather efficiencydriven or factor-driven instead of being innovation-driven to support social innovations (Blagov and Aray 2019, 170-5). However, major drivers of social entrepreneurship in Russia are the state (to support alternative solutions for main social problems) and large corporations (in the form of training, consulting, mentoring, project support and grants for social business), giving an impulse from the top. Mainly, social enterpreneurship in Russia focuses on the employment of citizens from any of the vulnerable categories and the realization of goods and services by and to the citizens of any vulnerable categories.

Moreover, there is a necessity to educate young generations with the idea that social problems can be solved by the state as well as with individuals and private business (Pecherskaya et al. 2019, 06003). In addition, the education system has to define a new value system, necessary knowledge, competencies, and skills to lead social business.

Nevertheless, Russian social entrepreneurship initiatives exist mainly as social startups that solve the problems of unemployment, education, environment, and health (Ivashchenko and Bulygina 2019, 119-23). One important idea is to educate unemployed women to become social entrepreneurs to solve unemployment in general and social problems to promote self-realization of certain social groups, career development, and local solutions for social needs (Voronkova et al. 2019, 1048-50). Furthermore, some researchers note that women's involvement rate in nonprofit organizations is higher than men's; women appreciate more social goals than economic profits in doing social business work (Huysentruyt 2014, 5-8). In these conditions, Russian social startups that help women, especially mothers, get employed under certain conditions, earn money, and take care of family at the same time, bringing a bigger social payoff. If social businesses face certain difficulties with the market, clients' demands, and lack of policies for work and distribution, such social startups have to be innovative and flexible in order to enter an existing market or even open up new markets.

Some scholars emphasiz the rapid development of environmental entrepreneurship in Russia as a type of social entrepreneurship that aims to solve environmental problems (Dudin et al. 2019, 1862-71; Filatova 2020, 11026). These activities can include ideas and technologies to reduce or eliminate companies' negative environmental impact, increase environmentally friendly production and distribution of goods and services, or popularize environmentally friendly practices and instruments.

This paper explores three main areas of social entrepreneurship in Russia: i) employment of socially disadvantaged and vulnerable groups; ii) various social services with the use of digital technologies for different consumer needs; and iii) development of social solidarity and support of disadvantaged and vulnerable groups. 


\subsection{Working places}

Goal №8 of seventeen sustainable development goals declared in 2015 aims to provide inclusive and sustainable economic growth, employment, and decent work for everyone. It explicitly concerns such social groups that, due to several reasons, have few or no chances in the job market to be employed regularly.

One such group are women on maternity leave. They often experience many difficulties getting a job; they mainly require part-time occupations due to the child care. Some have psychological problems connected to the new social role of a mother; others have difficulties coming back to the job market after a couple of years of staying at home. For example, the project "Mama rabotaet" (from the Russian »mom works «) helps women with kids to open their business; training, consulting, and online courses educate how to work remotely (MamaRabotaet n.d.). Moreover, this social business offers a database of vacancies andresumes to post and share; besides, there is a blog to share important and inspirational stories and an online learning platform to polish some skills.

Another group of people that needs some help with employment are people with special needs, in other words, people with some learning difficulties, emotional or behavioral problems, or physical disabilities. Employment of this category in Russia is working very badly; it is almost impossible for the disabled to get any job. Furthermore, these people often have no chances to study and train for a profession. So, social business can help them to learn necessary skills, get a job, earn money, and socialize. For example, the project «Naivno? Ochen« (from the Russian „Naive? Very much «) involves people with special needs in art practices. Ceramic, textile, printing and joinery creative workshops with online and offline shops sell their artworks; there is an art gallery for exhibitions, too (Naivno? Ochen n.d.). Online shops work for delivery and corporate business orders. This is an opportunity for people with special needs to express themselves in art practices, communicate with the different social environments, and get employed in the arts and social business.

Finally, older people need the attention of social entrepreneuship; they often feel lonely and have nothing to do when retired. The social enterprise 'BabaDeda' (from the Russian 'GrandmaGrandpa') offers an online information platform for elderly people to find different services, jobs, and new friends (BabaDeda n.d.). They provide articles and offers on tourism, insurance, sports, professional and free-time courses, culture, health, banking, and job offers. Many cities are represented there and post their offers online. In this way, older people can inform themselves about different activities, socialize, and even get employed for small services.

\subsection{Creative solutions for daily routine}

The social enterprises in this category reply to goals №3, »Good health and well-being; « №11, »Sustainable cities and communities; « №12, »Responsible consumption and production; « and №16, »Peace, justice and strong institutions « of the seventeen sustainable development goals. Creative ideas provide solutions for specific needs and demands and help people develop an understanding of a sustainable lifestyle.

In this context, one area that deserves attention is medical care; there are different demands from people with disabilities and from older people that social entrepreneurs can stimulate with innovations and experiments. The technology called »KnopkaZhizni« (from the Russian »Button for life«) is an emergency call for help for children, disabled, and elderly people (KnopkaZhizni n.d.). Implemented in regular watches, this button with geolocation based on artificial intelligence works through a computer application. This example demonstrates the combination of a social problem, social mission, and digital technologies that offer an effective solution.

Another area for social business in this category is implementing sharing practices as a contribution to the idea of responsible consumption. Sharing ideas replaces the traditional consumer paradigm and offer opportunities, not to buy new, but to use existing things, share the usage costs, or rent certain objects; the main goal is not to support the overproduction and overconsumption of goods and services. For example, the principle of transport sharing and saving the usage costs has its implementation in some applications in Russia, too. An online platform »Dublway» is a travel companion platform for city and city travel (Dublway n.d.). Anyone can offer a ride in a car or join other fellow travelers as a passenger. Drivers reduce fuel costs by sharing them with passengers who get a comfortable alternative to public transport. Moreover, the company actively collaborates with communities of people with disabilities.

Sharing practices also help to reduce waste production. So, various initiatives, with the help of digital technologies, offer services to prevent excessive waste production at the local level. For example, the application »Eatme« helps save food from restaurants and cafes (Eatme n.d.). The users through the app can buy dishes unsold during the day, with discounts of up to $80 \%$. The application already works in many Russian cities such as Moscow, St. Petersburg, Kazan, Nizhny Novgorod, and Sochi. So, the users join sharing community, learn how to reduce waste production, get some service with a discount-and all of these with the help of digital technologies. The popularization of responsible consumption practices raises ethical, responsible, or ecological production questions. Brands use different labels on the packaging in order to 
declare the principles of ethical, responsible, or ecological production. However, there is a problem of reliability and verification of such labels; Russia's lack of state policies to regulate its usage and the lack of control procedures make the process of choice for consumers often very complicated. One of the possible solutions comes with the application "EcolabelGuide." It is possible to scan any label on the packaging to check whether it is a credible ecolabel and what it means. This application helps consumers make the right choice if talking about ecologically produced products, fair labels, and the social responsibility of different companies.

One of the significant obstacles for positive and effective sustainable changes is communication difficulties between citizens and local administration. Lack of resources, budgetary constraints, an insufficient level of innovative development, and a low level of urban infrastructure development affect the quality of life in many cities in Russia. The social platform »iGrajdanin.ru" is an independent all-Russian Internet platform, a tool for organizing effective interaction between citizens and local authorities (iGrajdanin n.d.). With its help, citizens can directly contact local administrative services, municipal departments, and supervisory authorities and inform them about current urban problems (bad quality of roads, cars on lawns, unauthorized dumps). In turn, the authorities receive operational information and visual representation about the most urgent, from citizens' point of view, problems and the ability to respond more quickly to them. The platform offers to interact with local administrative institutions and find like-minded people to implement social projects.

\subsection{Social solidarity and support}

The initiatives to increase social solidarity and motivate people to support each other respond to the goals №11, "Sustainable cities and communities; « №12, »Responsible consumption and production; « №17, „Partnerships for the goals « of the seventeen sustainable development goals. Different practices organized by social entrepreneurs establish local communities, increase citizens' participation in various actions and initiatives, and build strong communication among citizens, businesses, and administrative institutions.

One of the ideas about social solidarity and support are donation practices. The mobile application "AdCharity « for Android devices allows users to transfer donations to charity funds. The users receive bonuses for viewing advertising banners on the smartphone, and can send these bonuses to any fund. Each banner view contributes to fundraising for a well-known charitable foundation (WWF, Vera Hospice Fund, Life Line, etc.); the user can choose any of them. The app users with active participation can accumulate bonuses monthly sufficient to transfer to charitable foundations. So far, AdCharity has transferred over half a million rubles to partner funds.
Another example is an online service, "Darudar, « a donation service where people can donate different goods such as clothes, accessories, furniture, electronic devices, etc. (Darudar n.d). This platform develops a donation economy and works on the popularization of new cultural values by increasing social interactions. The project emphasizes reducing inequality within and between countries, ensuring openness, security, and resilience of cities and towns, and ensuring sustainable consumption and production patterns. This idea also reflects the practices of waste reduction and against overconsumption caused by overproduction. Moreover, the project became international: more than 4400 cities worldwide joined the initiative.

Different strategies to attract people for supportive practices engage social business with innovative ideas. An online platform, »PosadiLes « (from the Russian »plant a tree«), is a permanent crowdfunding platform that aims to involve ordinary citizens in the topic of forest restoration (PosadiLes n.d.). The collected funds are directed to volunteer planting in fifteen regions of the Russian Federation; regional representatives organize this project. The users receive a certificate that they have contributed to tree planting. After the direct planting, the users receive per mail a report with a description of the planting, photo and video documentation, as well as the exact coordinates of the restored site. This initiative is highly promoted as an alternative to traditional gifts: instead of investing money in material objects, it is possible to invest in environmental projects.

Social solidarity and support initiatives can relate not only to humans but to animals. "Teddy food" is an online service where users help save animals from shelters across the country (TeddyFood n.d.). At the online platform in real-time, they can observe cats and dogs, feed and care for them remotely through intermediaries, paying for all services with special points. When the selected service is provided to the animal, the user will receive a report on the funds spent. Once again, digital technologies support and maintain social entrepreneurship and engage users in digital formats.

Another project called »Alturism« invites people to contribute to rural and tourism development (Alturism n.d.). It is a tourism project that facilitates Russian village restoration and development: from the online platform, it is possible to book tours to Russian villages, be hosted by locals, enjoy nature, and help in rural redevelopment (e.g., clearing the territory to further attract tourists, building a dam, or organizing a holiday). These activities help revitalize territories, attract investments, provide new working places, and build local communities. Moreover, it is possible to participate in the online course on small area development on the online platform. This social project emphasizes the necessity of rural development, the creation of new social and cultural values, local tourism development, and raises attention to the provincial area problems. 


\section{Conclusion}

This article introduced the idea that the application of digital technologies to social business will accomplish sustainable development goals. In particular, the article explained the importance of social and technological innovations in the modern business context. The focus on developing solutions for social problems, the realization of social mission, and engagement in global sustainable discussion allows social entrepreneurs to better contribute to the consumer demands and the changing market strategies. In turn, digital technologies, in the form of digital platforms, applications, and technological innovations provide original solutions to consumer demands and current social needs; besides, they contribute to the global sustainable discussion by optimizing business processes, including production and supply chain issues and communication with customers.

Social entrepreneurship in this context obtains better chances to implement and promote the results of innovative activities in the global market. Moreover, digital technologies used to implement the solutions for social needs help social businesses be as competitive and successful as other types of business models. Therefore, this article emphasizes the possibilities for social entrepreneurs to leverage technological innovations for leading sustainable transformation.

Special attention is given to the Russian context for developing social entrepreneurship. Some barriers and perspectives for expanding innovative social projects fulfil the Russian business environment. The research case of some Russian social entrepreneurship practices focuses on: i) ways to employ different social groups; ii) creation of solutions for everyday social needs; iii) initiatives to raise and deepen social solidarity and support in the society. Despite the difficulties with legal policies and insufficient governmental support for successful growth of social business, Russian social entrepreneurs demonstrate high potential and impressive innovativeness in dealing with social needs and consumer demands. The digitalization of Russian society has become the driving force for implementing social entrepreneurship practices in many areas of human activities.

\section{References}

Akhmetshin, Elvir M., Kseniya E. Kovalenko, Ludmila V., Goloshchapova, Aleksandra G. Polyakova, Elmira A. Erzinkyan, and Gulnaz M. Murzagalina. 2018. "Approaches to Social Entrepreneurship in Russia and Foreign Countries." Journal of Entrepreneurship Education 21(2): 1-10.

Alturism, n.d. Accessed December 12, 2021. https://www.altourism.ru/. BabaDeda, n.d. Accessed December 12, 2021. https://baba-deda.ru/.
Baden-Fuller, Charles, and Stefan Haefliger. 2013. "Business Models and Technological Innovation." Long Range Planning 46(6): 419-26. https://doi.org/10.1016/j.Irp.2013.08.023.

Blaga, Sorin. 2018. "A Business Model for Social Entrepreneurship Sustainability." Scientific Bulletin-Economic Sciences 17(2): 19-32. Blagov,Yury, and Yulia Aray. 2021. "Social Enterprise in Russia: Developing Social Entrepreneurship Models in the Russian Legal and Socio-Economic Context." In Social Enterprise in Central and Eastern Europe: Theory, Models and Practice,. Edited by Jacques Defourny and Marthe Nyssens, 169-83. Milton: Taylor \& Francis Group. https://doi.org/10.4324/9780429324529-12.

Calderini, Mario, Veronica Chiodo, Francesco Gerli, and Giulio Pasi. 2021. "Social-Tech Entrepreneurs: Building Blocks of a New Social Economy." Stanford Social Innovation Review. Last modified June 02, 2021. https://ssir.org/articles/entry/ social_tech_entrepreneurs_building_blocks_of_a_new_social_economy\#: :text=Social\%2Dtech\%20entrepreneurship $\% 20$ stands\%20in,\%2C\%20impact\%2Doriented\%20value\%20chain.

Changemakers, n.d. "Social Entrepreneurial Pathways to a Culture of Wellbeing.Social Innovation Mapping." Accessed December 09, 2021. https://wellbeing.changemakers.com/.

Choi, Nia, and Satyajit Majumdar. 2015. "Social Innovation: Towards a Conceptualisation." In Technology and Innovation for Social Change. Edited by Satyaj Majumdar, 7-34. New Delhi: Springer India.

Darudar, n.d. Accessed December 12, 2021. https://darudar.org/.

Dubleway, n.d. Accessed December 12, 2021. https://dublway.com/.

Dudin, M. N., N. P. Ivashchenko, A. G. Gurinovich, O. M. Tolmachev, and L. A.Sonina. 2019. "Environmental Entrepreneurship: Characteristics of Organization and Development." Entrepreneurship and Sustainability Issues 6(4): 1861-71. http://doi.org/10.9770/ jesi.2019.6.4(22).

Eatme, n.d. Accessed December 12, 2021. https://eatmeapp.ru/.

Filatova, Ulyana. 2020. "Environmental Entrepreneurship As a Type of Social Entrepreneurship." E3S Web of Conferences 164: 11026. https://doi.org/10.1051/e3sconf /202016411026.

Goyal, Sandeep, and Bruno S. Sergi. 2015. "Social Entrepreneurship and Sustainability-Understanding the Context and Key Characteristics." Journal of Security \& Sustainability Issues 4(3): 269-78.

Gregori, Patrick, and Patrick Holzmann. 2020. "Digital Sustainable Entrepreneurship: A Business Model Perspective on Embedding Digital Technologies for Social and Environmental Value Creation." Journal of Cleaner Production 272: 122817. https://doi. org/10.1016/j.jclepro.2020.122817.

Howaldt, Jürgen, Dmitri Domanski, and Christoph Kaletka. 2016. "Social Innovation: Towards a New Innovation Paradigm." RAM. Revista de Administração Mackenzie 17(6): 20-44. https://doi. org/10.1590/1678-69712016/administracao.v17n6p20-44.

Huysentruyt, Marieke. 2014. "Women's Social Entrepreneurship and Innovation." In OECD Local Economic and Employment Development (LEED) Papers, 5-8. 2014 (01). Paris: OECD Publishing. https://doi.org/10.1787/5jxzkq2sr7d4-en. 
iGajdanin, n.d. Accessed December 12, 2021. igrajdanin.ru. Ivashchenko, Natalia P., and Natalia I. Bulygina. 2019. "Social Entrepreneurship in Russia: Crrent State and Development Features." MIR (Modernization. Innovation. Research) 10(1): 114-32. (In Russian) https://doi.org/10.18184/2079-4665.2019.10.1.114-132. Jessop, Bob, Frank Moulaert, Lars Hulgård, and Abdellilah Hamdouch. 2013. "Social Innovation Research: A New Stage in Innovation Analysis." In The International Handbook on Social Innovation: Collective aAtion, Social Learning and Transdisciplinary Research, edited by Frank Moulaert et al., 110-30. Cheltenham, UK: Edward Elgar.

Khan, Syed Abdul Rehman, Pablo Ponce, Muhammad Tanveer, Nathalie Aguirre-Padilla, Haider Mahmood, and Syed Adeel Ali Shah. 2021. "Technological Innovation and Circular Economy Practices: Business Strategies to Mitigate the Effects of Covid-19." Sustainability 13(15): 8479. https://doi.org/10.3390/su13158479.

KnopkaZhizni, n.d. Accessed December 12, 2021. https://knopka24.ru/.

Lehtimäki, Hanna, Subhanjan Sengupta, Ville-Veiko Piispanen, and Kaisa Henttonen. 2021. "Social Entrepreneurship As Sustainability Agency." In Research Handbook of Sustainability Agency, edited by Teerikangas Satu, 168-79. Cheltenham, UK: Edward Elgar.

Liu, Zhiyang, Chenfang Zhao, and Bin Li. 2020. "Digital Social Entrepreneurship: Theoretical Framework and Research Outlook." Foreign Economics \& Management 42(4): 3-18. doi:10.16538/j. cnki.fem.20200228.402.

MamaRabotaet, n.d. Accessed December 12, 2021. https://mamarabotaet.ru/.

Masiero, Silvia, and M. N. Ravishankar. 2019. "Exploring Hybridity in Digital Social Entrepreneurship." In Information and Communication Technologies for Development. Strengthening Southern-Driven Cooperation as a Catalyst for ICT4D, edited by P. Nielsen and H. C. Kimaro 295-306. Cham : Springer . https://doi. org/10.1007/978-3-030-18400-1_24.

Moroni, Isabela, Amilton Arruda, and Katia Araujo. 2015. "The Design and Technological Innovation: How to Understand the Growth of Startups Companies in Competitive Business Environment." Procedia Manufacturing 3: 2199-2204. https://doi.org/10.1016/j. promfg.2015.07.361.
Moskovskaya, A. A., and I. V. Soboleva. 2016. "Social Entrepreneurship in the System of Social Policy: International Experience and Prospects of Russia. "Studies on Russian Economic Development 27: 683-88. https://doi.org/10.1134/S1075700716060113.

Mulgan, Geoff, Simon Tucker, Rushanara Ali, and Ben Sanders. 2007. "Social Innovation: What It Is, Why It Matters and How It Can Be Accelerated." Working paper. London: Young Foundation.

Muralidharan, Etayankara, and Pathak Saurav. 2018. "Sustainability, Transformational Leadership, and Social Entrepreneurship." Sustainability 10: 567. https://doi.org/10.3390/su10020567.

Naivno?Ochen, n.d. Accessed December 12, 2021. https://naivno. $\mathrm{com} /$.

Pecherskaya, E. P., T. M. Tarasova, E. A. Timofeeva, and V. G. Zarubin. 2019. "Mission of Social Entrepreneurship in Modern Russia." SHS Web of Conferences 6 : 06003. https://doi.org/10.1051/ shsconf/20196206003.

PosadiLes, n.d. Accessed December 12, 2021. http://posadiles.ru/.

Prodanov, Hristo. 2018. "Social Enterpreneurship and Digital Technologies." Economic Alternatives 1: 123-38.

Rahdari, Amir, Sepasi Sahar, and Mohammad Moradi. 2016. "Achieving Sustainability through Schumpeterian Social Entrepreneurship: The Role of Social Enterprises." Journal of Cleaner Production 137: 347-360. https://doi.org/10.1016/j.jclepro.2016.06.159.

Salim Saji, Beena, and Paul Ellingstad. 2016. "Social Innovation Model for Business Performance and Innovation." International Journal of Productivity and Performance Management 65(2): 256-74. https://doi.org/10.1108/lJPPM-10-2015-0147.

TeddyFood, n.d. Accessed December 12, 2021. https://teddyfood. $\mathrm{com} / \mathrm{ru} /$.

Torres, Pedro, and Mário Augusto. 2020. "Digitalisation, Social Entrepreneurship and National Well-Being." Technological Forecasting and Social Change 161 120279. https://doi.org/10.1016/j.techfore.2020.120279.

Voronkova, Olga, Valerry Nikishkin, Irina Frolova, Elena Matveeva, Gulnaz Murzagalina, and Ervena Kalykova. 2019. "Importance of the Process of Teaching the Basics of Social Entrepreneurship for the Sustainable Development of Society." Entrepreneurship and Sustainability Issues 7(2): 1048-58. https://doi.org/10.9770/ jesi.2019.7.2(18). 